\title{
FORMULATION AND EVALUATION OF TOPICAL HERBAL GEL FOR TREATMENT OF ACNE
}

Sushmitha K R, Manjunath K*, Suresh V Kulkarni

Department of Pharmaceutics, Sree Siddaganga College of Pharmacy. B.H Road, Tumkur-572102 Karnataka, India.

Article Info: Received 03 June 2019; Accepted 26 June. 2019

DOI: https://doi.org/10.32553/jbpr.v8i3.605

Address for Correspondence: Kopparam Manjunath, Department of Pharmaceutics, Sree Siddaganga College of Pharmacy, Tumkur, Karnataka, India.

Conflict of interest statement: No conflict of interest

\section{ABSTRACT:}

The objective of the study was to develop a topical herbal gel for the treatment of mild acne vulgaris. Aqueous extracts Withania somnifera formulated using different gelling agent like carbopol-934, Xanthan gum, \& HPMC K100 M. Nine formulations of the gel were prepared by varying the proportions of polymer and evaluated for their physicochemical properties like appearance, $\mathrm{pH}$, spreadability, viscosity, assay, and microbial assay. FTIR studies reveals that there was no interaction between the Withania somnifera and selected polymers Carbopol 934, Xanthan gum and HPMC K 100 M. In vitro drug diffusion studies showed percentage CDR of $100.16 \%$ at the end of 3 hours. The microbial assay of all the formulations demonstrated better inhibitory activity against Staphylococcus epidermidis compared to the marketed clindamycin phosphate gel. The stability study carried out of the selected gel F2 at room temperature and $40 \pm 2{ }^{\circ} \mathrm{C} / 75 \pm$ $5 \% \mathrm{RH}$ was found to be stable for a period of 45 days in terms of drug content, physical appearance and $\mathrm{pH}$ etc. Based on these results, Formulation F2 containing $1.5 \%$ carbopol-934 was selected as best formulation.

Key words: Herbal gel, Withania somnifera, In vitro diffusion, Zone of inhibition.

\section{Introduction}

Skin is the most important part of our body but daily exposing the skin leads the many skin problems, acne vulgaris is most common among them. It is an inflammatory disease of sebaceous follicles of skin marked by comedones, papules and pustules and presence of bacterias Propionibacterium acne, Staphylococcus epidermidis and Malassezia furfur in follicular canal. Acne is a disease of pilobaceous glands. Multiple factor responsible for pathogenesis of acne as sebum, abnormal follicular differentiation, hormones, propionibacterium acne, inflammation and nutrition ${ }^{1}$.

Skin is one of the most readily accessible organs on human body for topical administration. The skin often has been referred to as the largest of the body organ. An average adult's skin has surface area of $2 \mathrm{~m}^{2}$ and receives about one third of the blood circulation through the body. Gels are defined as semisolid system in which a liquid phase is constrained within a polymeric matrix in which a high degree of physical and chemical cross-linking introduced ${ }^{2}$.

Herbal medicine play an important role now a days $^{3}$, World Health Organization suggest that 4 billion people, who make nearly $70 \%$ of the world's population, are users of herbal medicine for some purpose of primary health care. Medicinal herbs have always been in usage in some form or the other in indigenous systems of medicines including Ayurveda, Sidha and Unani in India. An increasing number of companies are making forays into the herbal market segment ${ }^{4}$.

Withania somnifera has been used as an antioxidant, adaptogen, aphrodisiac, liver tonic, anti-inflammatory agent and astringent and more recently as an antibacterial, antihyperplycemic anti antitumoral as well as to treat ulcers and senile dementia $^{5}$. Most of its biological activities have been attributed to the presence of group of compounds referred as withanolides. The roots and leaves of withania are used as drugs. Various 
withanolides have been isolated from Withania somnifera, withaferin $A$ and 3 3 -hydroxy-2,3 dihydro withanolides $F$ show promising antibacterial, antitumour, immunomodulating antiinflammatory properties.

In the present study we aimed to develop Withania somnifera aqueous gel using suitable polymers and evaluate the developed formulations for required characteristics.

\section{MATERIALS AND METHODS}

\section{Materials}

All the chemicals used were of analytical grade and Witahania somnifera obtained from the Swapnaroop Drugs and Pharmaceuticals.

\section{Determination of Withania Somnifera $\lambda \max$ in Phosphate buffer at $\mathbf{p H} \mathbf{7 . 2}$}

Stock solution: Accurately weighed quantity of 100 mg Withania somnifera was taken in $100 \mathrm{ml}$ volumetric flask and was dissolved by using $5 \mathrm{ml}$ of methanol, finally the volume was made up with 7.2 $\mathrm{pH}$ phosphate buffers up to $100 \mathrm{ml}$ to produce 1 $\mathrm{mg} / \mathrm{ml}$ of solution.

Scanning: From stock solution $50 \mu \mathrm{g} / \mathrm{ml}$ were prepared by using above stock solution and scanned between 200-800 $\mathrm{nm}$. The absorption maxima of $275 \mathrm{~nm}$ was selected and used for further studies (Figure1).

\section{Preparation of gel with Carbopol 934}

Accurately weighed Carbopol 934 was taken in a beaker and dispersed in $50 \mathrm{ml}$ of distilled water. Kept the beaker aside to swell the Carbopol for half an hour and then stirred using mechanical / lab stirrer at $1200 \mathrm{rpm}$ for $30 \mathrm{~min}$. Propylene glycol 5 $\mathrm{ml}$ and required quantity of extract was taken. Propylene glycol $5 \mathrm{ml}$ was taken in another beaker and added weighed quantity of propyl paraben and methyl paraben to it and stirred properly. After carbopol dispersed, $1 \mathrm{gm}$ extract and preservatives solutions were added with constant stirring. Finally volume made upto $100 \mathrm{ml}$ by adding remaining distilled water and Triethanolamine was added drop wise to the formulations for adjustment of required skin $\mathrm{pH}(6.8-7)$ and to obtain the gel at required consistency (Table1).

\section{Preparation of gel with HPMC K 100 M}

Accurately weighed $1 \mathrm{gm}$ of extract was transferred to a beaker and dissolved in $10 \mathrm{ml}$ of propylene glycol into which preservatives were added. HPMC $\mathrm{K} 100 \mathrm{M}$ was made to disperse in distilled water then heated up to $80-90^{\circ} \mathrm{C}$ with continuous stirring and it was allowed to cool. Extract loaded propylene glycol solution were added to HPMC K $100 \mathrm{M}$ preparation and stirred vigorously to mix in cold condition and water was added to make up the volume up to $100 \mathrm{ml}$ and stirred in mechanical stirred well to get a uniform gel.

\section{Preparation of gel with Xanthan gum}

Accurately weighed Xanthan gum was taken in a beaker and dispersed in $50 \mathrm{ml}$ of distilled water. Kept the beaker aside to swell the Xanthan gum for half an hour and then stirring should be done using mechanical / lab stirrer at $1200 \mathrm{rpm}$ for $30 \mathrm{~min} .5$ $\mathrm{ml}$ of propylene glycol and required quantity of Extract. $5 \mathrm{ml}$ propylene glycol taken in another beaker and add weighed quantity of propyl paraben and methyl paraben to it and stirred properly. After Xanthan gum dispersed, Extract and preservatives solutions were added with constant stirring.

\section{Evaluation of the gel}

Physical appearance and homogeneity was observed after the preparation. Colour of the formulations was checked out against white background. The consistency and greasiness was assessed by the application on to the skin. Odour of the gels was checked by mixing the gel in water and observed the smell.

\section{Determination of $\mathrm{pH}$}

About $20 \mathrm{mg}$ of the formulation was taken in a beaker and was subjected to the $\mathrm{pH}$ measurement using a digital $\mathrm{pH}$ meter within 24 hours of preparation.

\section{Drug content analysis}

The drug content of the formulations was determined by dissolving an accurately weighed quantity of gel $1 \mathrm{gm}$ in $100 \mathrm{ml}$ of solvent (phosphate buffer $\mathrm{pH}$ 7.2). The solutions were kept for shaking for 4 hours and then kept for 6 hours for complete dissolution of the formulations. Then the solutions were filtered through $0.45 \mu \mathrm{m}$ membrane filters and proper dilutions were made and solution was subjected to the 
spectrophotometric analysis. The drug content was calculated from the linear regression equation obtained from the calibration data.

\section{Spreadability}

It was determined by wooden block and glass slide apparatus. For the determination of Spreadability 1 gm of sample was applied in between two glass slides and was compressed to uniform thickness by placing $100 \mathrm{gm}$ weight over top glass slide for 5 minutes. Weight (30 gm) was added to pan which was used as standard weight for all formulations and pan was tied to upper glass slide. The time required to move the distance of $6 \mathrm{~cm}$, i.e. the time in which the upper glass slide moves $6 \mathrm{~cm}$ over the lower glass slide was taken as measure of Spreadability (S). Spreadability was calculated by using the formula

$\mathrm{S}=\mathrm{ML} / \mathrm{T}$

Where, $\mathrm{M}=$ Weight tide to upper slide

$L=$ Length moved on the glass slide

$\mathrm{T}=$ Time taken to move $6 \mathrm{~cm}$ distance.

\section{Extrudability}

Extrudability test was carried out by using Pfizer hardness tester. A $40 \mathrm{gm}$ of gel was filled in aluminium and plastic collapsible tube. The plunger was adjusted to hold the tube properly. The pressure of $1 \mathrm{~kg} / \mathrm{cm}^{2}$ was applied for $30 \mathrm{sec}$. The quantity of gel extruded was weighed. The procedure was repeated at three equidistance places of the tube. Test was carried out in triplicates.

\section{Viscosity measurement}

Viscosity of gels was determined by using Brookfield (DV-II+ Pro viscometer) viscometer. The gel was placed in the sample holder and the suitable spindle selected (spindle no. T-F) was lowered perpendicularly into the sample. The spindle was attached to viscometer and then it was allowed to rotate at $20 \mathrm{rpm}$ speed at room temperature. The gel was subjected to a torque ranging from 10 to $100 \%$. The readings of viscosity of the formulation were measured after 2 minutes.

\section{In vitro drug release studies}

In vitro drug release experiment was carried out by using fabricated Franz diffusion cell. The dialysis membrane -70 (Hi-Media) (pore size of $2.4 \mathrm{~nm}$, molecular weight cut-off between 12,000 - 14,000) was previously soaked in phosphate buffer $\mathrm{pH} 7.2$ and it was clamped between the receptor and donor compartments in order to attain $37 \pm 2$ oC. The receptor compartment was filled with $22 \mathrm{ml}$ of diffusion medium (Phosphate buffer $\mathrm{pH}$ 7.2) by taking care to remove all the air bubbles. Accurately weighed $1 \mathrm{gm}$ gel was placed on the dialysis membrane. A quantity of $2 \mathrm{ml}$ samples were withdrawn from the receptor fluid at the time intervals of 5, 30, 60, 90, 120,150 and $180 \mathrm{~min} \mathrm{~nm}$ and $2 \mathrm{ml}$ of phosphate buffer of $\mathrm{pH} 7.2$ was replaced immediately each time. The drug release was estimated by using spectrophotometer at 275 $\mathrm{nm}$.

\section{Stability studies}

Stability is defined as the extent, to which a product retains with in specified limits and throughout its period of storage i.e. shelf life. Stability studies were carried out an optimized formulation according to international conference on Harmonization (ICH) guidelines. The selected formulation was filled in 2 different collapsible tubes (Lami tube and aluminium collapsible tube) and subjected to a stability testing for 45 days at a temperature (room temperature and $40 \pm 2{ }^{\circ} \mathrm{C}$ ). At each station (every month for 3months) selected formulation was analyzed for the change in $\mathrm{pH}$, Spreadability, extrudability, homogeneity, viscosity and drug content by procedure stated earlier.

\section{Antibacterial Studies}

The solutions of the gels were prepared using 100 $\mathrm{mg}$ of gel in $10 \mathrm{ml}$ of dimethyl sulfoxide. The antibacterial activity was tested by well diffusion method. Staphylococcus aureus was incubated in ASLA agar medium for 48 hours under anaerobic conditions and adjusted to yield approximately $1 \times 108 \mathrm{CFU} / \mathrm{ml}$. The solidified agar plates were swabbed with inoculums on the surface. The equidistance wells were cut in the plates with help of $8 \mathrm{~mm}$ borer. In each of these wells the gel solutions in DMSO were placed and the plates were left at ambient temperature for $30 \mathrm{~min}$ to allow pre diffusion prior to incubation at $37{ }^{\circ} \mathrm{C}$ for $72 \mathrm{hrs}$ under anaerobic conditions in a anaerobic bag ( $\mathrm{Hi}$ Media) with gas pack and the bag was kept in an incubator for 72 hours at $37 \pm 1{ }^{\circ} \mathrm{C}$. 
The culture of Staphylococcus epidermidis was prepared in nutrient agar medium at 24 hours under aerobic conditions. Test samples of this aerobic bacterium were incubated at $37{ }^{\circ} \mathrm{C}$ for 24 hours under aerobic conditions. Marketed clindamycin phosphate gel was taken as reference product. The anti- bacterial activity was estimated by measuring the diameter of the zone of inhibition. All well diffusion tests were performed in three separate experiments and antibacterial activity was expressed as the mean \pm standard deviation.

\section{RESULTS AND DISCUSSION}

The formulation development work was preceded by pre-formulation studies in order to characterize and estimate the suitability for its inclusion into an aqueous gel system. Characteristic peaks of Withania somnifera shown in Figure 2A confirms the identity of the herbal extract of Withania somnifera. These peaks are retained in the physical mixture of Withania somnifera and selected polymers Figure 2B. Hence, FTIR studies reveals that there was no interaction between the Withania somnifera and selected polymers Carbopol 934, Xanthan gum and HPMC K 100 M.

All the formulations were brown in colour and had characteristic odour of Withania somnifera. All formulations were glossy and translucent. Formulation F2, F6 was found to have excellent consistency and $\mathrm{F} 4$ had good consistency. The $\mathrm{pH}$ of the formulation ranged from 6.7-7.5, which may be suitable for topical application without discomfort. The Spreadability of the formulations was found to range from $41.5 \pm 0.7$ to $46.5 \pm 0.4$ $\mathrm{g} / \mathrm{sec}$. The viscosity was observed to increase with decrease in the spreadability and vice-versa. Formulation F4, F5 and F7 were found to have excellent extrudability and F1, F2, F6 and F8 had good consistency (Table 2).

The drug content in dermatological bases was found to range from $92.98 \pm 0.22-102 \pm 0.80 \%$. This proved that the method was suitable for the preparation of topical dosage forms. As indicated by the value of the drug content, there was no degradation of drug during the preparation process. Cumulative drug diffusion after 3 hours was found to be $100.16 \%$ for F2 (Figure 3). This is ascribed to the increased drug diffusion from the gel due to its low viscosity, soft nature and the nature of gelling agent used. Thus the formulation with the $1.5 \mathrm{gm}$ carbopol content (F2) was found to have the most optimized results. The results from the stability studies showed that formulations showed no changes in the $\mathrm{pH}$, viscosity, spreadability, consistency, extrudability and drug content, hence formulations are found to be stable.

In vitro diffusion data of the optimized formulation of Withania somnifera extract, Fomulation F2 was subjected to kinetic models as zero order, first order, Higuchi and Peppas model (Figure 4). Higher correlation, as indicated by $\mathrm{R}^{2}$, was observed for the Higuchi release kinetics in the optimized formulation, suggesting diffusion as a probable prominent mechanism of drug release (Table 3 ). In diffusion, the rate of drug dissolution within the matrix must be much higher than that of the diffusion rate of the drug leaving the matrix. This may be attributed to the nature of gelling agent used.

When formulations were subjected to antimicrobial investigation, then it was found that all had inhibitory against Staphylococcus aureus and Staphylococcus epidermidis. Among all the formulations, the formulations F2, F5 and F8 had shown good zone of inhibition, it was also observed that F2 had shown the zone of inhibition against Staphylococcus epidermidis greater than that of herbal marketed clindamycin phosphate gel (Figure 5). However, prepared formulations showed lesser zone of inhibition against Staphylococcus aureus than the marketed clindamycin phosphate gel. (Table 4).

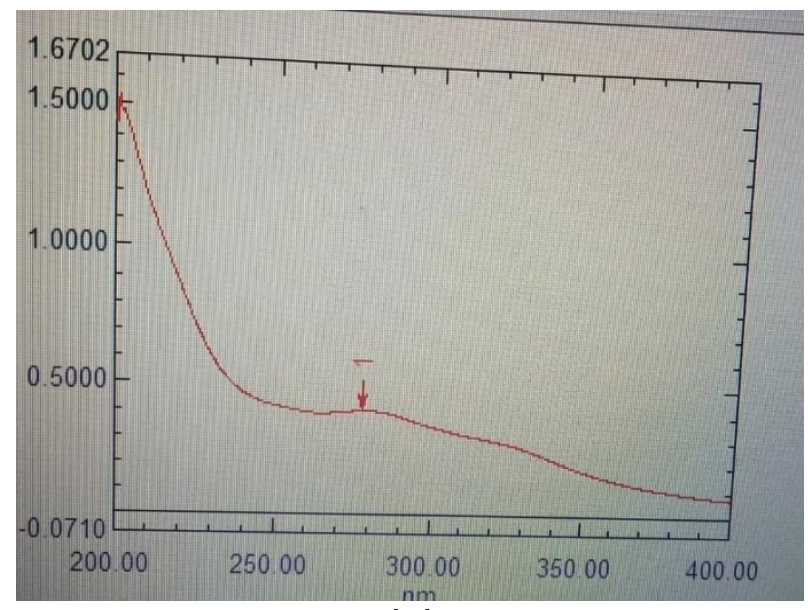

(A) 
Kopparam Manjunath et al., Journal of Biomedical and Pharmaceutical Research

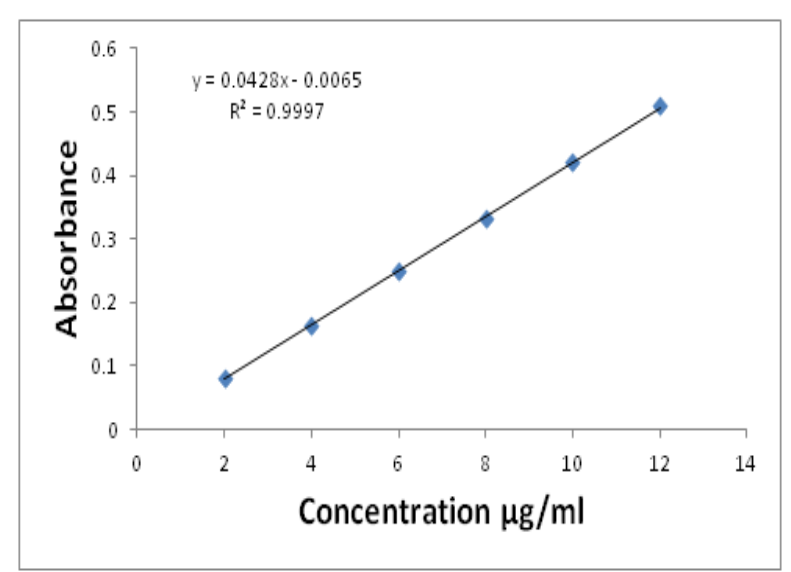

(B)

Figure 1: (A) Determination of witahnia somnifera $\lambda$ max in phosphate buffer pH 7.2, (B) Standard graph of withania somnifera in phosphate buffer pH 7.2.

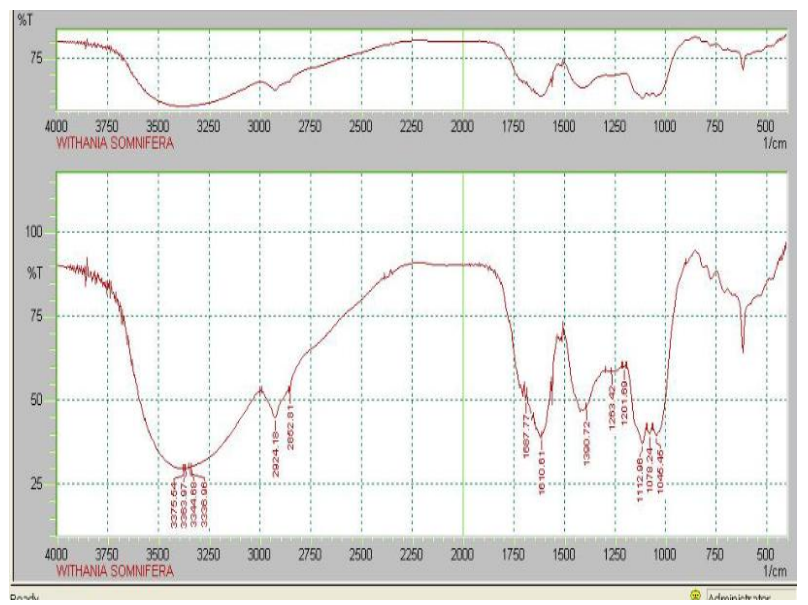

(A)

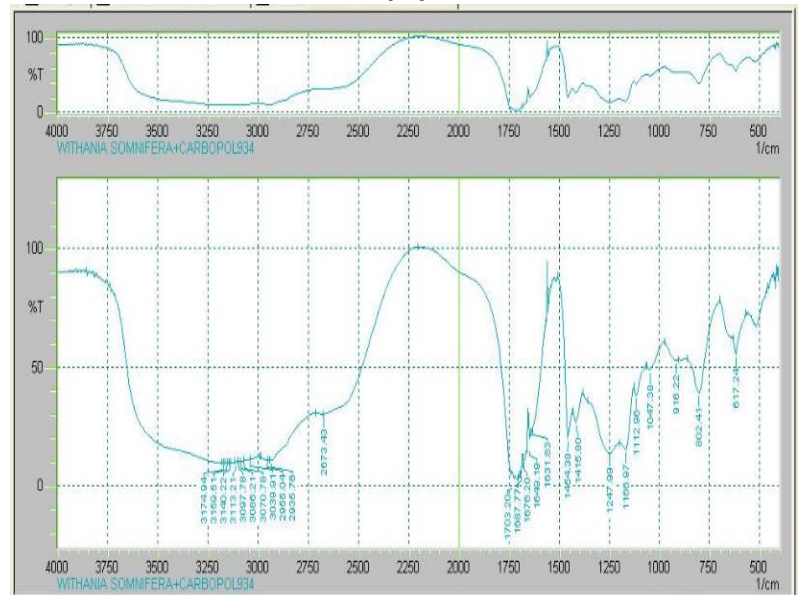

(B)

Figure 2: (A) FTIR Spectrum of pure Withania somnifera, (B) FTIR Spectrum of physical mixture of Withania somnifera + Carbopol 934.

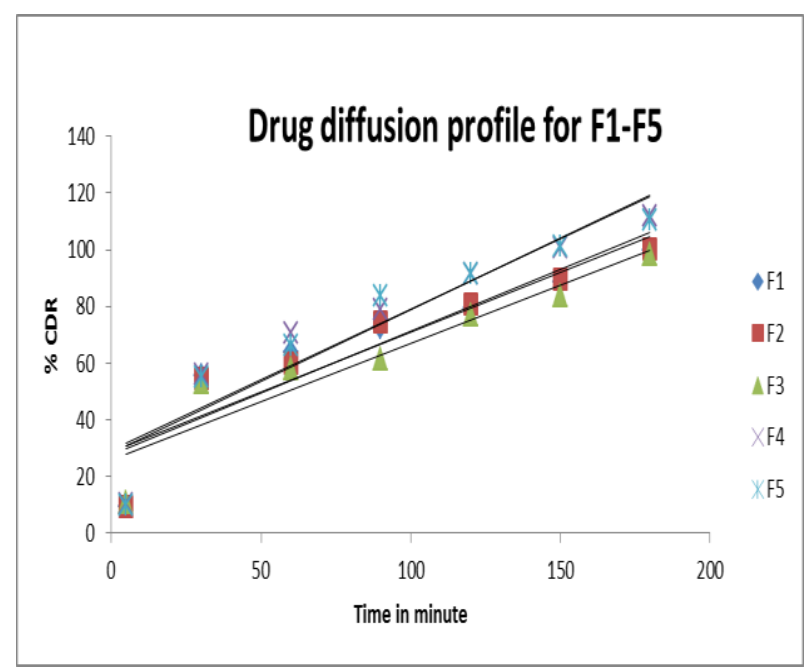

(A)

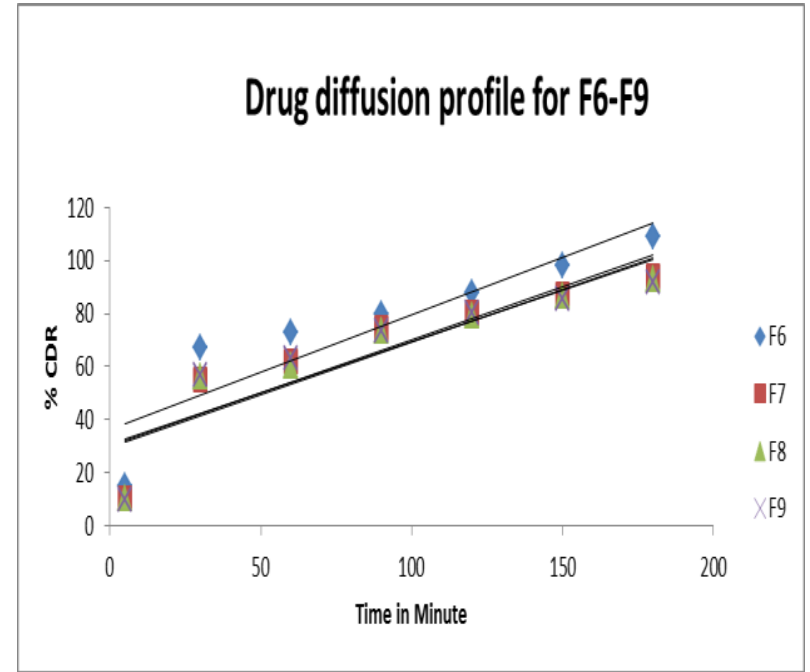

(B)

Figure 3: (A) Percentage drug release of formulations F-1 to F-5, (B) Percentage drug release of formulations F-6 to F-9.

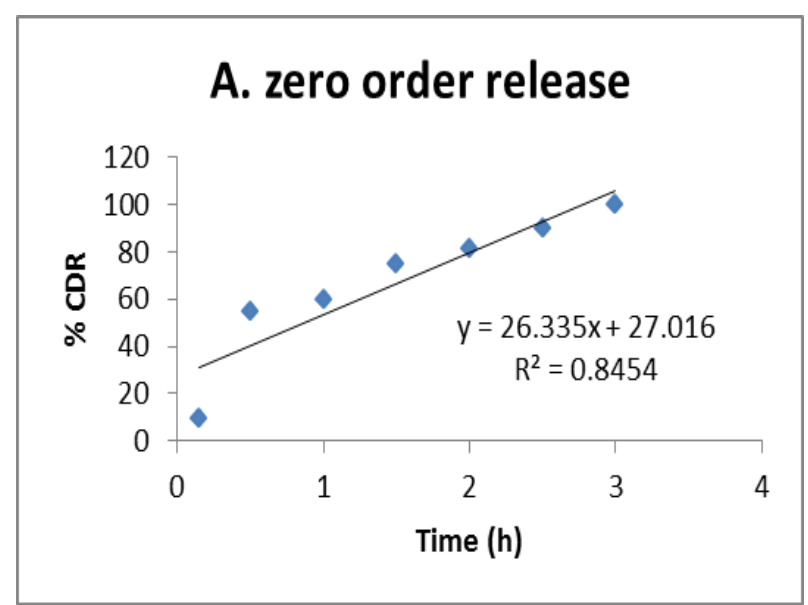

(A) 


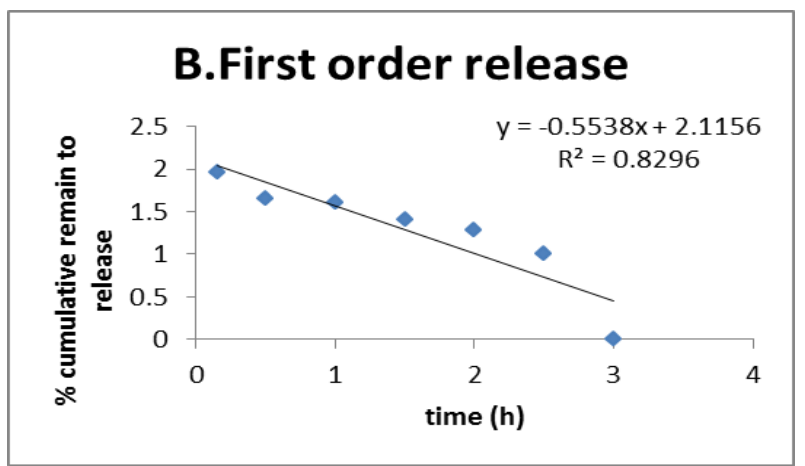

(B)

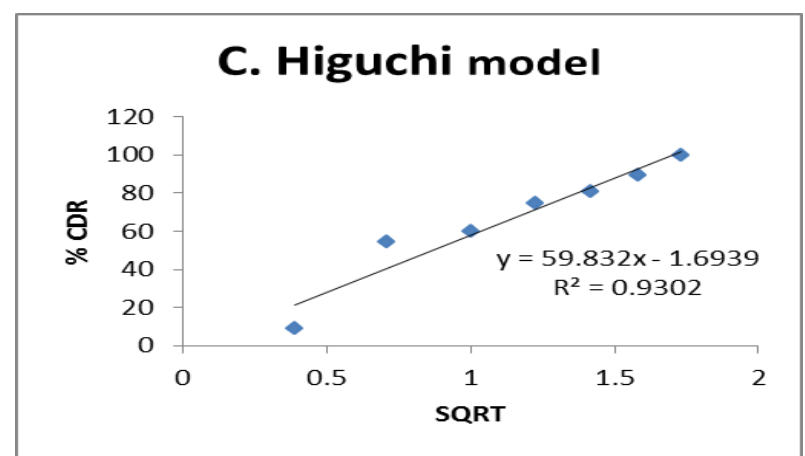

(C)

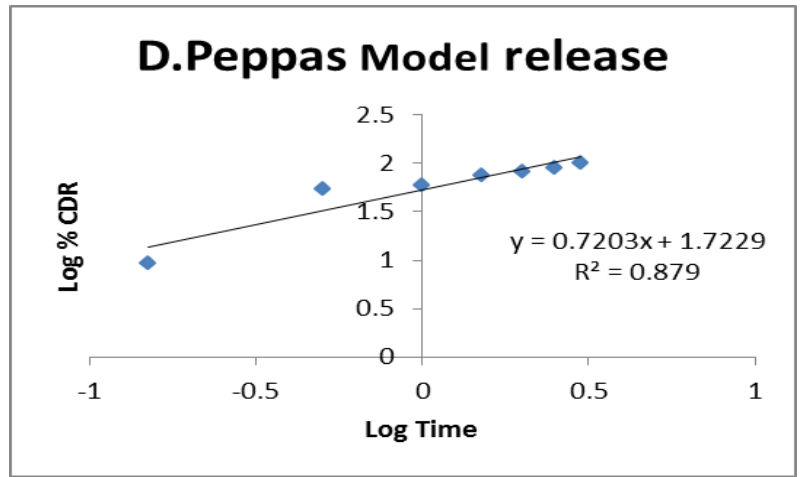

(D)

Figure 4(A,B,C,D): Fitting of in vitro drug release data into zero order, first order, Higuchi and Peppas models.

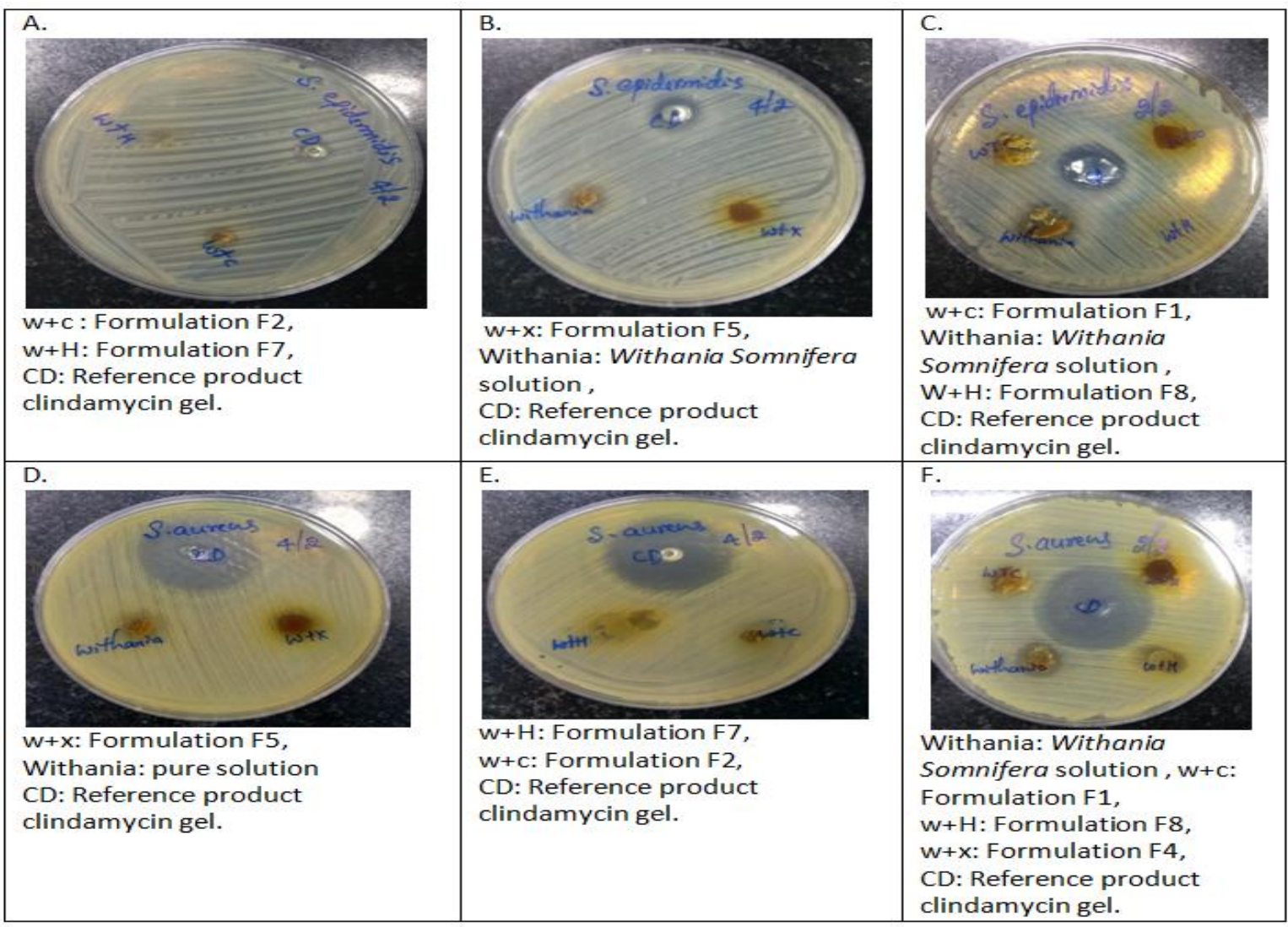

Figure 5: Zone of inhibition of Withania somnifera gel formulations against Staphylococcus epidermidis \& Staphylococcus aureus. 
Kopparam Manjunath et al., Journal of Biomedical and Pharmaceutical Research

Table 1: Composition of Withania somnifera gel using various polymers as gel forming agents.

\begin{tabular}{|l|l|l|l|l|l|l|l|l|l|}
\hline Ingredients & F1 & F2 & F3 & F4 & F5 & F6 & F7 & F8 & F9 \\
\hline Withania somnifera (gm) & 1 & 1 & 1 & 1 & 1 & 1 & 1 & 1 & 1 \\
\hline Carbopol 934 (gm) & 1 & 1.5 & 2 & - & - & - & - & - & - \\
\hline Xanthan gum (gm) & - & - & - & 1 & 1.5 & 2 & - & - & - \\
\hline HPMC K 100 M (gm) & - & - & - & - & - & - & 1 & 1.5 & 2 \\
\hline Aloe extract (gm) & 0.5 & 0.5 & 0.5 & 0.5 & 0.5 & 0.5 & 0.5 & 0.5 & 0.5 \\
\hline EDTA (gm) & 0.05 & 0.05 & 0.05 & 0.05 & 0.05 & 0.05 & 0.05 & 0.05 & 0.05 \\
\hline Polyethylene glycol (ml) & 5 & 5 & 5 & 5 & 5 & 5 & 5 & 5 & 5 \\
\hline Methyl paraben (gm) & 0.2 & 0.2 & 0.2 & 0.2 & 0.2 & 0.2 & 0.2 & 0.2 & 0.2 \\
\hline Propyl paraben (gm) & 0.02 & 0.02 & 0.02 & 0.02 & 0.02 & 0.02 & 0.02 & 0.02 & 0.02 \\
\hline Triethanolmine (ml) & 1 & 1 & 1 & - & - & - & - & - & - \\
\hline Distilled water q.s. to (ml) & 100 & 100 & 100 & 100 & 100 & 100 & 100 & 100 & 100 \\
\hline
\end{tabular}

Table 2: pH, Extrudability, Drug content and Spreadability of various formulations.

\begin{tabular}{|l|l|l|l|l|}
\hline Formulation code & $\mathbf{p H}$ & Extrudability & $\begin{array}{l}\text { Drug content } \\
\text { (\%) }\end{array}$ & $\begin{array}{l}\text { Spreadability } \\
\text { (cm/sec) }\end{array}$ \\
\hline F1 & $6.8 \pm 01$ & Good & $93.84 \pm 1.33$ & $41.5 \pm .5$ \\
\hline F2 & $6.8 \pm 07$ & Good & $98.97 \pm 2.22$ & $43.1 \pm .2$ \\
\hline F3 & $7.1 \pm 04$ & Fair & $97.06 \pm 0.55$ & $46.5 \pm .2$ \\
\hline F4 & $7.2 \pm 01$ & Excellent & $99.81 \pm 0.55$ & $44.2 \pm .3$ \\
\hline F5 & $7.4 \pm 08$ & Excellent & $101 \pm 1.60$ & $46.0 \pm .3$ \\
\hline F6 & $7.5 \pm 01$ & Good & $102 \pm 0.80$ & $47.6 \pm .0$ \\
\hline F7 & $6.5 \pm 04$ & Excellent & $94.87 \pm 2.22$ & $42.0 \pm .1$ \\
\hline F8 & $6.8 \pm 06$ & Good & $93.84 \pm 1.33$ & $44.2 \pm .5$ \\
\hline F9 & $6.7 \pm 03$ & Fair & $92.98 \pm 0.22$ & $48.3 \pm .0$ \\
\hline
\end{tabular}

Table 3: Processing of release data for release kinetics of Formulation F2.

\begin{tabular}{|l|l|l|l|l|l|l|}
\hline $\begin{array}{l}\text { Time } \\
\text { (h) }\end{array}$ & Log time & SQRT & $\begin{array}{l}\text { Percentage } \\
\text { cumulative release }\end{array}$ & $\begin{array}{l}\text { Log of percentage } \\
\text { release }\end{array}$ & $\begin{array}{l}\text { percentage drug } \\
\text { remaining }\end{array}$ & $\begin{array}{l}\text { Log percentage drug } \\
\text { remaining }\end{array}$ \\
\hline 0 & 0 & 0 & 0 & -- & 100 & 2 \\
\hline 0.25 & -0.602 & 0.500 & 9.39 & 0.973 & 90.61 & 1.95 \\
\hline 0.5 & -0.301 & 0.707 & 54.76 & 1.738 & 45.24 & 1.65 \\
\hline 1 & 0.000 & 1.000 & 59.89 & 1.777 & 40.11 & 1.60 \\
\hline 1.5 & 0.176 & 1.225 & 74.67 & 1.873 & 25.33 & 1.40 \\
\hline 2 & 0.301 & 1.414 & 81.0 & 1.909 & 18.99 & 1.27 \\
\hline 2.5 & 0.398 & 1.581 & 89.7 & 1.953 & 10.3 & 1.01 \\
\hline 3 & 0.477 & 1.732 & 100.16 & 2.001 & -0.16 & - \\
\hline
\end{tabular}

Table 4: Zone of inhibition of various formulations against staphylococcus epidermis and Staphylococcus aureus.

\begin{tabular}{|c|c|c|c|c|c|c|c|c|c|c|}
\hline Formulation code & F1 & $F 2$ & F3 & $F 4$ & F5 & F6 & $F 7$ & F8 & $F 9$ & Clindamycin Marketed gel \\
\hline \multirow{4}{*}{ Zone of inhibition $(\mathrm{cm})$} & \multicolumn{10}{|c|}{ Against Staphylococcus epidermis } \\
\hline & 0.9 & 1.1 & 0.7 & 0.4 & 0.5 & 0.2 & 0.5 & 0.1 & 0.4 & 0.8 \\
\hline & \multicolumn{10}{|c|}{ Against Staphylococcus aureus } \\
\hline & 0.2 & 0.4 & 0.2 & 0.3 & 0.4 & 0.3 & 0.1 & 0.1 & 0.2 & 2.2 \\
\hline
\end{tabular}




\section{CONCLUTION}

It can be concluded from the present investigation that proper selection of polymers and drug is a prerequisite for designing and developing a topical drug delivery system. Prior to formulation, pre formulation studies were carried out in order to establish compatibility between drug and excipients by IR spectroscopy. The results of IR study revealed that there is no physical or chemical interaction between drug and excipients. The herbal extracts of Withania somnifera and Aloe vera contained in an aqueous based gel system can successfully inhibit the acne producing bacteria like Staphylococcus epidermidis. Aqueous herbal extracts can be successfully formulated using suitable gel forming polymers specifically for topical therapies not requiring systemic absorption. The formulated topical herbals can be used in conjunction with systemic antibiotics for successful anti-acne therapy.

\section{REFERENCES}

1. Aditi V, Pranav S. Formulation \& evaluation of anti-acne formulation of coriander extract. Int. J. Pharm. Sci. Res. Rev 2012;16(2):97-103.

2. Chinembiri $T$, Gerber $M$, Plessis $L H$, Preez JL, Hamman JH, Plessis J. Topical delivery of Withania somnifera crude extracts in niosomes \& solid lipid nanoparticles. Pharmacogn Mag 2017;13(3):489-16.

3. Mahendran S, Fouzia HAH. Formulation \& evaluation of natural anti-acne cream containing Syzygium samarangense fruit extract. ARRB 2017;17(3):1-7.

4. Supriya A, Sharad W, Anoop A. Formulation \& evaluation of herbal anti acne gel of Myrica esculenta. Asian J Pharm Clin Res 2016;9(4):358-61.

5. Srivastava A, Alam S, Shams S, Tiwari M, Mittal A, Sanjeev C. Formulation \& evaluation of antiacne cream containing Withania somnifera. JPSI 2014;3(4):348-52. 